\title{
Management of post-traumatic pseudarthrosis of tibia with free non-vascularised fibular strut graft: A case report.
}

\author{
Dr.Ghaniuzzoha Asadi ${ }^{1}$, Dr.Ramakant Bhivsan ${ }^{2}$, Dr.Ketan Kodare ${ }^{3}$, Dr.Nikhil Lakade ${ }^{4}$ \\ (Department Of Orthopaedics, GMC Aurangabad, Maharashtra, India).
}

\begin{abstract}
Post-traumatic pseudarthrosis of tibia is a known complication of open tibial fractures in adults usually occurring from high velocity injuries due to road traffic accidents. We report a case of post traumatic neglected, severely angulated, grossly deformed pseudarthrosis non union of tibia successfully managed with the use of free non-vascularised fibular strut graft.At surgery, the sclerotic fracture fragments were excised,angulation corrected and ipsilateral free non-vascularised fibular strut graft harvested \& inserted in the medullary cavity of tibia augmented by simple uniplanar external pin fixator for mechanical stabilization.Three months after surgery radiograph showed uniting fracture and at four months external fixator was removed.At six months it showed solid union with well functioning limb.
\end{abstract}

Keywords: external fixator, non-vascularised, pseudarthrosis, sclerotic surface, union.

\section{Introduction}

Post-traumatic pseudarthrosis non-union of tibia is a challenging problem in orthopaedic practice.Several surgical methods are available for its treatment[1] : Excision of sclerotic ends followed by bone grafting/free vascularised fibular grafts or bone transport with an Ilizarov ring fixator.Most commonly used methods of treatment are different modifications of Ilizarov technique,vascularised fibular grafting and bone grafting with intramedullary fixation[2].Many studies have demonstrated the effectiveness of autogenous cortical bone[3,4].Ilizarov bone transport is a good alternative but it is heavy,cumbersome,complicated,lengthy, time consuming procedure to plan and construct frame and associated with risk of neurovascular damage by traversing pins.Although free vascularised bone grafts have been advocated recently[5],the older method of using autogenous non-vascularised bone graft is still successful and that is the purpose of this case report.

\section{Case Report}

A 35 year old female presented to orthopaedic opd with a two year old post traumatic severely angulated,grossly deformed, shortened, pseudarthrosis non union of the junction of middle one third and distal one third of tibia(Fig 1a).Overlying soft tissue was contracted and scarred(Fig 1b).She had a history of road traffic accident two years back and sustained open fracture of tibia which was managed with wound debridement and external fixator.After some time,as the wound healed,the fixator was removed but she did not comply with further definitive management of fracture and neglected it.Now she has presented for correction of deformity and angulation \& union of fracture.A decision was made to excise the sclerotic fracture fragments, correction of angulation followed by non-vascularised fibular strut grafting augmented with simple uniplanar external pin fixator for mechanical stabilization. The posterolateral approach used to expose the middle two third of tibia (because the skin over the subcutaneous surface was badly scarred).Under Tourniquet, the internervous plane between the gastronemius,soleus,flexor hallucis longus \& the peroneal muscles utilized and posterior surface of tibia exposed.

The pseudoarthrosis identified,the sclerotic fracture fragments were excised,angulation corrected.About 6-8 $\mathrm{cm}$ of ipsilateral fibula in middle one third was dissected subperiosteally, then was osteotomised proximally and distally with saw.After preparation of the bone ends of the gap,the medullary cavity of both ends was opened and the fibular strut graft was snugly fit into the medullary cavity proximally and distally.Mechanical stabilization was achieved using simple uniplanar external pin fixator with three pins in proximal fragments and two in distal fragments. An image intensifier was used to confirm the desired position of fragments and the pins.Incision closed in layers.procedure went uneventful.Immediate post-surgical corrected angulation of leg(Fig 2a) and post-operative radiograph recorded(Fig 2b).Sutures removed after two weeks. Serial radiographs were taken and monthly followup of the patient done.Patient was asked to do vigorous knee and ankle range of motion exercises post-operatively to prevent stiffness of knee and equines deformity of ankle. She was kept nonweight bearing for first three months.At three months after surgery,radiograph showed uniting fracture (Fig 3a $\& 3 \mathrm{~b}$ ) and at four months, external fixator was removed.Patient was given a custom made shoe with $5 \mathrm{cms}$ elevation to compensate for the difference in the length of the lower extremities.Walking exercises were started under supervision of physiotherapist.At six months the fracture showed solid union,patient was able to walk with shoe raise, without problems and the leg was pain free.(Fig $4 a \& 4 b$ ). 

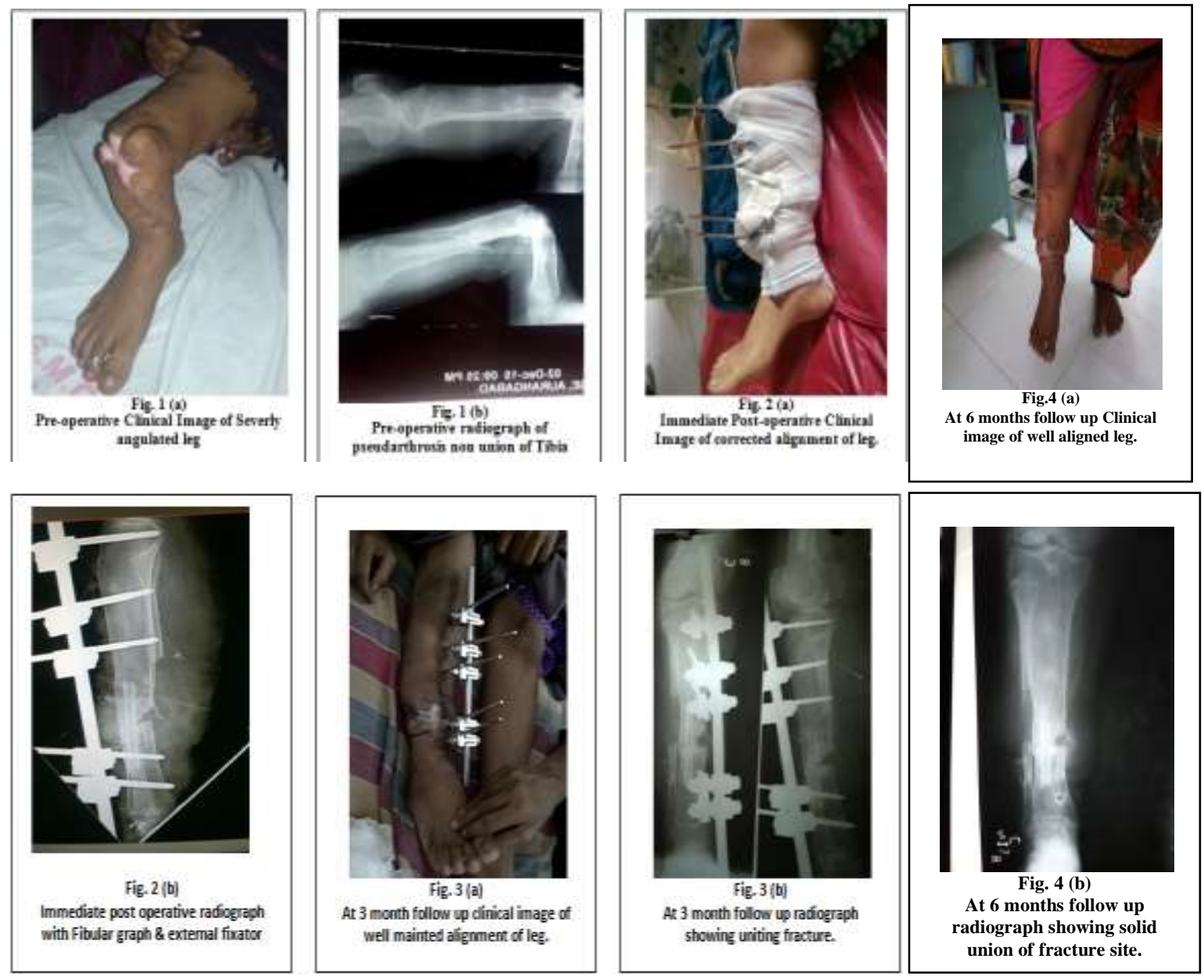

\section{Conclusion}

In 1877 Albert first proposed the use of the fibula as a graft.Since then the fibula has been used to reinforce a weakened section providing structural support[6].Several studies have shown that vascularised grafts are significantly stronger than conventional non-vascularised grafts[7].However in this case bony union occurred by six months with non vascularised graft.Al-Zahrani et.al[8] achieved excellent primary union in patients treated by non-vascularised single fibular strut graft.Also Omolou[9] succeded in bridging a tibial gap in patients treated by a non-vascularised fibular graft.Morsi[10] achieved fracture union in patients treated by contralateral non-vascularised fibular graft.Hence in our opinion free non vascularised fibular strut graft is a simple procedure that is still a valid option to successfully manage post-traumatic pseudarthrosis non-union of tibia.

\section{References}

[1]. De Boer HH,Wood MB. Bone changes in the vascularised fibular graft.J.Bone Joint.Surg.1989;71-B:374-378.

[2]. Delgado-Martinez AD,Rodriguez-Merchan EC,Olsen B. Pseudoarthrosis Of Tibia,1996;20;192-199.

[3]. Enneking WF,Eady JL,Burchardt H. Autogenous Cortical bone grafts in the reconstruction of segmental skeletal defects.J.Bone Joint Surg.1980;62A: 1039-1058.

[4]. Mnaymneh W.Malinin T.Makley JT,Dick HM. Massive osteoarticular allografts in the reconstruction of extremities Clin Orthop $1985 ; 197 ; 76-87$

[5]. Weiland AJ,Moore JR,Daniel RK. Vascularised bone autografts : experience with 41 cases.Clin Orthop $1983 ; 174$ : 87-95.

[6]. Hertel R,Pisan M,Jakob RP.Use of the ipsilateral vascularised fibula for tibial reconstruction.J.Bone Joint Surg. 1995; 77B;914-919.

[7]. Nather A.Goh JCH,Lee JJ. Biomechanical strengthof non-vascularised diaphyseal bone transplant.J Bone Joint Surgery 1990; 72 B ; 1031-1035.

[8]. Al Zahrani S.et.al.Free fibular graft still has a place in the treatment of bone defects,Injury 1993 24;551-554.

[9]. Omolou B,Ogunlade SO,Alonge TO. Limb conservation using non-vascularised fibular graft. West Afr J Med 2002; $21 ; 347-349$.

[10]. Morsi E. Tibial reconstruction using a non-vascularised fibular transfer.Int Orthop 2002; $26 ; 377-380$.Epub 2002-2006. 